\title{
PERCEPÇÃO DOS AGRICULTORES DO MUNICÍPIO DE IMIGRANTE (RS) SOBRE OS RISCOS DA EXPOSIÇÃO A AGROTÓXICOS
}

PERCEPTION OF FARMERS OF IMIGRANTE CITY (RS) ABOUT THE RISK OF EXPOSURE TO PESTICIDES

\section{Mônia Graziela Wahlbrinck}

Bióloga pelo Centro

Universitário Univates -

Lajeado (RS), Brasil.

\section{Jonas Bernardes Bica}

Biólogo e Mestre em Ambiente

e Desenvolvimento Centro

Universitário Univates -

Lajeado (RS), Brasil.

\section{Claudete Rempel}

Bióloga pelo Centro Universitário Univates e Doutora em Ecologia pela Universidade Federal do Rio Grande do Sul (UFRGS) e Professora do programa de pós-graduação em Ambiente e Desenvolvimento e do mestrado em Sistemas Ambientais Sustentáveis do Centro Universitário Univates Lajeado (RS), Brasil.

Endereço para correspondência: Claudete Rempel - Rua São Pedro, 1190 - Moinhos - 95900-000 Lajeado (RS), Brasil E-mail: crempel@univates.br

Recebido: 19/01/2016

Aceito: 08/05/2017

\begin{abstract}
RESUMO
Desde o início do uso de agrotóxicos no Brasil, sua aplicação vem aumentando. Eles acarretam danos à saúde humana e ao ambiente natural. O presente estudo teve como objetivo verificar a percepção de agricultores do município de Imigrante (RS) sobre os danos causados pelos agrotóxicos à saúde humana e ao meio ambiente. Foram entrevistados 130 agricultores cadastrados na Secretaria Municipal de Agricultura de Imigrante (RS). Os agricultores foram visitados nos meses de julho e agosto de 2015, quando responderam a um questionário, composto por 25 questões. As respostas foram tabuladas e analisadas por meio de estatística descritiva. Os dados demonstram que a maioria dos agricultores são homens que não leem os rótulos e a bula dos agrotóxicos. Além disso, a utilização dos equipamentos de proteção individual (EPIs) é realizada de maneira parcial, bem como a forma como descartam as embalagens dos agrotóxicos é inadequada, o que gera, além de efeitos nocivos à saúde, a predisposição ao descuido em relação à contaminação do meio ambiente. Observa-se, a partir dos questionários, que os agricultores conhecem os problemas que os agrotóxicos podem gerar ao meio ambiente e à sua saúde, no entanto, não relacionam o uso inadequado dos agrotóxicos com seu estado de saúde.
\end{abstract}

Palavras-chave: agroquímicos; defensivos agrícolas; saúde; meio ambiente.

\section{ABSTRACT}

Since the beginning of pesticide use in Brazil, its application has been increasing. They cause harm to human health and to the natural environment. This study aimed to verify the perception of farmers in the municipality of Imigrante (RS) about the damage caused by pesticides to human health and to the environment. 130 registered farmers were interviewed in the municipal department of agriculture in Imigrante (RS). The farmers were visited in July and August 2015 and answered to a questionnaire containing 25 questions. The answers were tabulated and analyzed using descriptive statistics. The data demonstrate that the majority of farmers are men who do not read the labels and instructions of pesticides. In addition, the use of personal protective equipment (PPE) is partially accomplished, as well as the way that the packaging of pesticides is discarded improperly, which generates, besides harmful health effects, predisposition to carelessness in relation to contamination of the environment. It is observed from the questionnaires, that farmers know the problems that pesticides can cause to the environment and to health, however, they do not relate the inappropriate use of pesticides to their health.

Keywords: agrochemicals; pesticides; health; environment. 


\section{INTRODUÇÃO}

Na intenção de aumentar a produtividade e modernizar a agricultura, teve início na década de 1950, nos Estados Unidos, uma grande mudança no processo de produção agrícola, denominada Revolução Verde (SILVA et al., 2005). Na essência dessa modernização estava um progressivo processo de automação das lavouras, com uso de maquinários e de produtos agroquímicos no processo de produção (PERES \& MOREIRA, 2003).

No Brasil, a Revolução Verde teve início na década de 1960 e adquiriu força em meados de 1970 com a criação do Programa Nacional de Defensivos Agrícolas (PNDA) (PREZA \& AUGUSTO, 2012). Um dos objetivos do PNDA era o estímulo ao aumento da produção com consequente elevação na utilização nacional de agrotóxicos, cujo crédito rural era concedido ao agricultor, sendo que este tinha que empregar parte dos recursos na compra de agrotóxicos. Entretanto, a política de modernização da agricultura, que subsidiou o crédito e incentivou a implantação da indústria de defensivos agrícolas no Brasil, acabou por ignorar diversos fatores importantes como o despreparo da mão de obra, não oferecendo ao trabalhador rural capacitação e treinamento necessários para a aplicação dessas novas tecnologias (SOARES et al., 2005). As vendas de agrotóxicos movimentam bilhões de dólares em todo o mundo, e, conforme dados obtidos em estudos da consultoria alemã Kleffmann Group, em 2008, o Brasil foi considerado o maior mercado consumidor de agrotóxicos do planeta, sendo que naquele ano a indústria movimentou US\$ 7,1 bilhões (PACHECO, 2009).

O modelo de produção agrícola brasileiro, historicamente, baseou-se no uso de agrotóxicos para compensar problemas do processo produtivo. Nesse contexto, os agrotóxicos foram introduzidos na agricultura brasileira como uma tentativa de prevenir e eliminar as pragas que prejudicariam a produtividade (VEIGA, 2007). $\mathrm{O}$ uso indevido de agrotóxicos contribui imensamente para a degradação ambiental, além de ser constante a ocorrência de intoxicações durante o seu manuseio, constituindo assim um dos principais problemas de saúde pública do meio rural do país. Souza et al. (2011) descrevem que ainda são escassos os estudos de base populacional sobre as características da utilização ocupacional ou sobre as intoxicações por agrotóxicos.
O termo agrotóxico, em vez de defensivo agrícola, passou a ser utilizado no Brasil para denominar os venenos agrícolas somente após grande mobilização da sociedade civil organizada, sendo que este termo coloca em evidência a toxicidade desses produtos para o meio ambiente e a saúde humana (SIQUEIRA \& KRUSE, 2008).

De acordo com a Lei Federal $n^{0} 7.802$, de 11 de julho de 1989 (BRASIL, 1989) regulamentada por meio do Decreto $\mathrm{n}^{0}$ 4.074, de 4 de janeiro de 2002 (BRASIL, 2002) (antes regulamentada pelo Decreto $n^{\circ}$ 98.816) agrotóxicos são

\begin{abstract}
produtos e agentes de processos físicos, químicos ou biológicos, destinados ao uso nos setores de produção, no armazenamento e beneficiamento de produtos agrícolas, nas pastagens, na proteção de florestas, nativas ou plantadas, e de outros ecossistemas e de ambientes urbanos, hídricos e industriais, cuja finalidade seja alterar a composição da flora ou da fauna, a fim de preservá-las da ação danosa de seres vivos considerados nocivos, bem como as substâncias e produtos empregados como desfolhantes, dessecantes, estimuladores e inibidores de crescimento.
\end{abstract}

Os agrotóxicos são classificados, de acordo com o fim a que se destinam controlar, em: inseticidas, fungicidas, herbicidas, desfolhantes, fumigantes, rodenticidas e raticidas, moluscocidas, nematicidas e acaricidas. Existem cerca de 300 princípios ativos em duas mil formulações comerciais diferentes, classificados quanto à sua ação e ao grupo químico a que pertencem, sendo utilizados no país (STOPPELLI \& MAGALHÃES, 2005).

Embora a produção de agrotóxicos seja realizada para afetar alvos específicos como insetos, ácaros e fungos, essa seletividade nunca é atingida, pois a história evolutiva dos seres vivos os tornam parecidos nas características bioquímicas e fisiológicas, sendo que diversos dos componentes celulares ou das vias metabólicas, que são alvos dos princípios ativos dos agrotóxicos, são parecidos com os que se encontram nos seres humanos (PREZA \& AUGUSTO, 2012).

A exposição aos agrotóxicos tem se configurado um sério problema de saúde pública (PREZA \& AUGUSTO, 2012). A Organização Mundial de Saúde (OMS) define saúde como um estado de completo bem-estar físico, mental e social, e não consiste apenas na ausência de doença ou de enfermidade (OMS, 1946). A abordagem pode ter sido considerada avançada na época em 
que foi proposta, no entanto, autores como Segre \& Ferraz (1997) a consideram irreal, ultrapassada e unilateral. Este conceito pode ser considerado utópico, à medida que leva a uma condição de equilíbrio que não condiz com o modo de viver atual (ANDRADE, 2006; MENICUCCI, 2009), além de ser questionável uma definição de perfeito bem-estar (SEGRE \& FERRAZ, 1997). Segundo a Agência Nacional de Vigilância Sanitária (Anvisa), o conceito proposto pela OMS tem profunda relação com o desenvolvimento e expressa a associação entre qualidade de vida e a saúde da população. A saúde, nesse sentido, é resultado de um processo de produção social e sofre influência de condições de vida adequadas de bens e serviços (ANVISA, 2009). Em relação ao uso de agrotóxicos, pouco se sabe sobre a ação de uma exposição continuada a compostos sobre o corpo humano ainda em desenvolvimento e que diversas substâncias usadas como agrotóxicos são suspeitas de apresentarem atividade carcinogênica ou hormonal (MOREIRA et al., 2002).

Considerando que os agrotóxicos são uma realidade constante e cada vez mais presentes na prática da agricultura, deveriam ser criadas estratégias educacionais para que o aplicador possa optar por produtos menos tóxicos e sempre estar informado sobre mudanças e desenvolvimento de práticas alternativas no controle de pragas (LYZNICKI, 1997).

O uso de agrotóxicos tem aumentado porque é dito ao produtor que apenas com os mesmos é possível uma produção em larga escala, devido ao combate de agentes patógenos (LEITE \& SERRA, 2013). Para a maioria dos trabalhadores rurais, uma cultura agrícola sem a presença de agrotóxicos não seria uma alternativa viável e seu uso se tornou comum, inclusive em pequenos municípios (VEIGA, 2007).
O Vale do Taquari é composto por 36 municípios e é uma região de tradição agrícola, na qual a economia da maioria dos municípios está baseada no setor primário, caracterizando-se predominantemente pela agricultura familiar.

Para a região do Vale do Taquari não foram encontradas pesquisas referentes à percepção dos agricultores sobre os riscos que o uso de agrotóxicos pode oferecer, somente investigações com cultivos específicos e sobre os problemas e impactos que eles podem causar à saúde, conforme os estudos de Souza et al. (2011) e Troian et al. (2009). Souza et al. (2011) realizaram pesquisa para avaliar a possível associação entre contato com agrotóxicos e prevalência de doenças crônicas na população rural em três municípios do Vale do Taquari e constataram que o contato direto ou indireto com agrotóxicos se associou ao relato de diversas doenças, sendo as neurológicas e as orais as mais citadas. O estudo de Troian et al. (2009) versava sobre o uso de agrotóxicos na produção do fumo, na cidade de Arvorezinha (RS).

Existe necessidade de diminuir o impacto do uso de agrotóxicos no meio ambiente e, por conseguinte, na saúde pública. Para isso, é necessário que se tenha conhecimento de como os agricultores estão fazendo emprego desses produtos químicos na prática da agricultura. Conhecer de forma detalhada os fatores que interferem na percepção dos trabalhadores, em relação aos riscos a que estão expostos no ambiente de trabalho, transforma-se em uma ferramenta essencial para os que pretendem construir uma atividade educativa realmente transformadora junto a esse público (GARCIA \& ALVES FILHO, 2005). Assim, o objetivo do presente estudo foi verificar a percepção de agricultores do município de Imigrante (RS) sobre os danos causados pelos agrotóxicos à saúde humana e ao meio ambiente.

\section{PROCEDIMENTOS METODOLÓGICOS}

O estudo foi desenvolvido com agricultores do município de Imigrante (Figura 1, elaborado por Zerwes et al., 2015). O município de Imigrante, localizado na região do Vale do Taquari, no Estado do Rio Grande do Sul, Brasil, possui uma população de 3.146 habitantes e área de 73,36 km² (IBGE, 2015).
A base da economia do município de Imigrante está diretamente ligada à agricultura e pecuária, baseada na pequena propriedade rural. Conforme levantamentos realizados pelo Instituto Brasileiro de Geografia e Estatística (IBGE) em 2010, residiam na área rural do referido município 1.524 habitantes, e conforme dados de 2015, da Secretaria Municipal da Agricultura, Meio 
Ambiente e Desenvolvimento Econômico, o município possui em torno de 400 propriedades rurais ativas com seus respectivos grupos familiares. Para uma amostra com $95 \%$ de confiança e $7 \%$ de erro, selecionaram-se, de forma aleatória, 130 agricultores e, destes, incluídos os que possuíam inscrição estadual de produtor rural junto ao município e que fazem uso de agrotóxico em sua propriedade.

Os agricultores participantes da pesquisa foram visitados nos meses de julho e agosto de 2015 e respon-

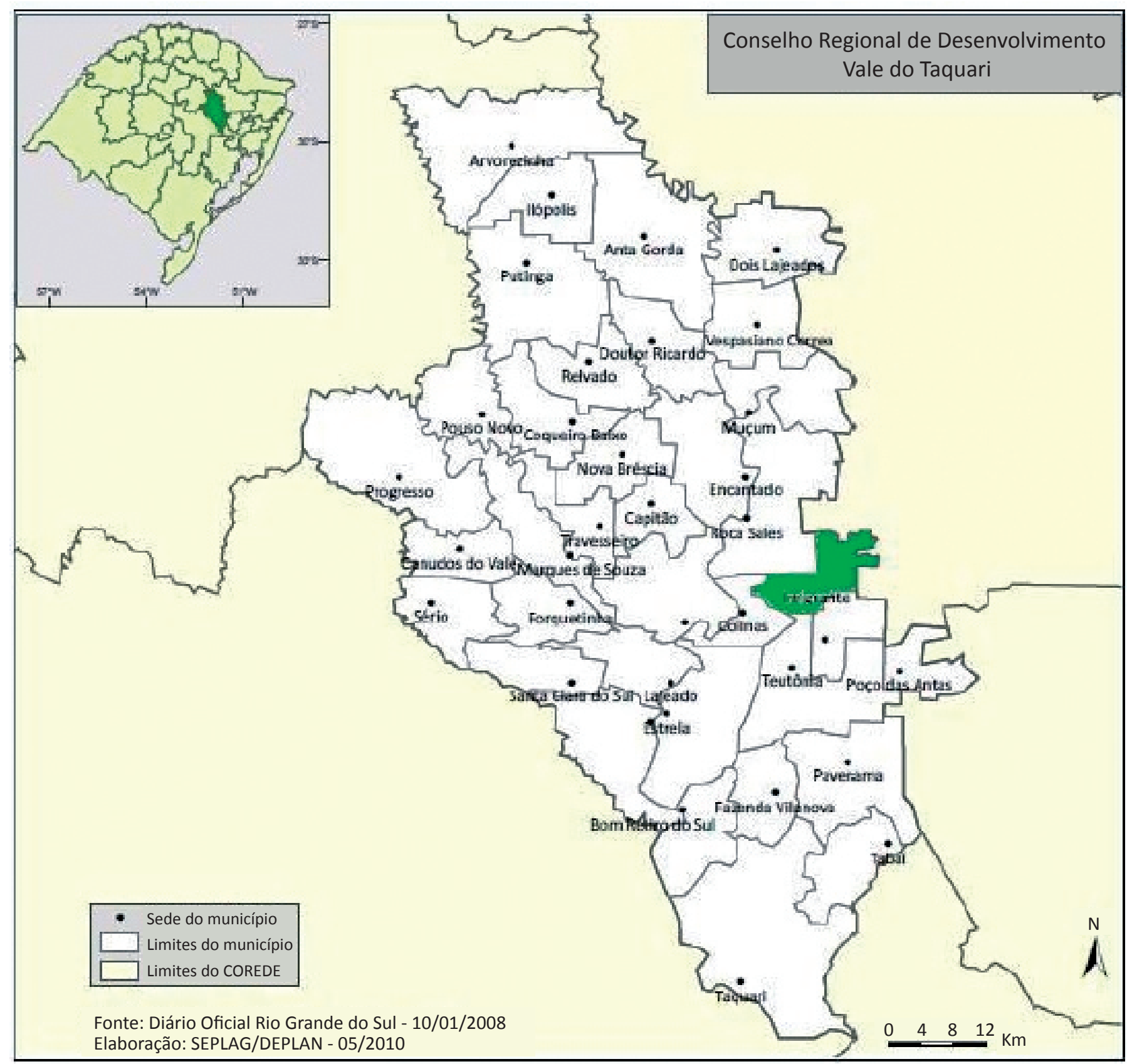

Legenda: Município de Imigrante (RS).

Fonte: Zerwes et al. (2015).

Figura 1 - Área do estudo. 
deram a um questionário, composto por 25 questões, lido pelas pesquisadoras, que assinalaram as respostas dadas pelos participantes da investigação.

As questões versavam sobre o perfil do trabalhador (cinco questões):

- a utilização de agrotóxicos (oito questões);

- a saúde do trabalhador (cinco questões);

- a segurança do trabalhador (cinco questões) e
- a higiene do trabalhador (duas questões).

Tabularam-se e analisaram-se os dados obtidos com os questionários por meio de estatística descritiva no Microsoft Excel, sendo as frequências apresentadas na forma percentual (\%) e os dados de tendência central, na forma de média (desvio padrão).

Este estudo seguiu os preceitos éticos da Resolução do CNS n 466/2012 e foi aprovado pelo Comitê de Ética da Univates, sob o protocolo $n^{\circ}$ CAAE 45636215.6.0000.5310.

\section{RESULTADOS E DISCUSSÃO}

A análise do perfil dos participantes do estudo mostrou que, dos 130 agricultores entrevistados, 122 $(93,8 \%)$ eram do sexo masculino. A média da idade dos indivíduos foi de 54,7 (DP 10,4) anos). Em relação à aquisição da propriedade, $111(85,4 \%)$ se declararam proprietários das terras cultivadas e 19 (14,6\%) filhos de proprietários. Quanto ao nível de escolaridade, nenhum dos agricultores se revelou analfabeto, sendo que $108(83,1 \%)$ possuem Ensino Fundamental incompleto e apenas quatro $(3,1 \%)$ concluíram o Ensino Médio. Nenhum dos entrevistados possui Ensino Superior. A maioria declara que começou a trabalhar desde a infância na propriedade, e, de acordo com as respostas, a média de idade dos que começaram a trabalhar na propriedade rural foi de 12 (DP 3,3) anos. Os dados socioeconômicos podem ser visualizados na Tabela 1 .

Tabela 1 - Dados socioeconômicos dos produtores rurais de Imigrante (RS).

\begin{tabular}{|l|c|c|}
\hline Variável & n & $\%$ \\
\hline Sexo & 122 & 93,8 \\
\hline Masculino & 8 & 6,2 \\
\hline Feminino & & 0,0 \\
\hline Escolaridade & 0 & 83,1 \\
\hline Analfabeto & 108 & 10,0 \\
\hline Ensino Fundamental incompleto & 13 & 3,8 \\
\hline Ensino Fundamental completo & 5 & 3,1 \\
\hline Ensino Médio incompleto & 4 & 0,0 \\
\hline Ensino Médio completo & 0 & 85,4 \\
\hline Ensino Superior & & 14,6 \\
\hline Relação de trabalho & 111 & 0,0 \\
\hline Proprietário & 19 & Desvio padrão \\
\hline Filho de proprietário & 0 & 10,4 \\
\hline Empregado & Média & 3,3 \\
\hline Variável & 54,7 & 6,1 \\
\hline Idade & 12,0 & 18,1 \\
\hline Média de idade com a qual começou na atividade rural & & \\
\hline Tempo médio de utilização de agrotóxico (em anos) & & \\
\hline
\end{tabular}


Estudos realizados por Oliveira-Silva et al. (2001) relacionaram o impacto da contaminação humana por agrotóxicos a fatores socioeconômicos, como renda familiar, nível educacional e habilidade de leitura e escrita. Os agricultores entrevistados, embora não sejam analfabetos, possuem baixo grau de instrução, o que pode prejudicar a compreensão da bula do agrotóxico, por exemplo.

Quando os agricultores foram questionados a respeito do tempo que faziam uso de agrotóxicos, obtevese uma média de 18,1 (DP 6,1) anos, sendo que 93,8\% dos pesquisados afirmam utilizar agrotóxico entre 10 e 30 anos. Dados que se equiparam com estudo realizado por Bedor et al. (2009), em que $62,0 \%$ dos entrevistados utilizam agrotóxicos há cerca de 10 a 30 anos.

Grande parte dos agricultores de Imigrante $(89,2 \%)$ diz ter conhecimento sobre os riscos que o uso de agrotóxicos pode ocasionar e nenhum afirma comer ou fumar durante a aplicação dos mesmos. Outros estudos também apontam que boa parte dos agricultores reconhece que a exposição a agrotóxicos pode ocasionar danos à saúde (PERES et al., 2004; RECENA \& CALDAS, 2008; RANGEL et al., 2011; ALVES et al., 2013).

Em relação ao armazenamento dos agrotóxicos, 112 agricultores $(86,2 \%)$ relatam que armazenam o produto em local adequado, a uma distância segura de crianças, alimentos e fontes de água, o que vai ao encontro dos estudos realizados no município de Chapecó (SC), que apontam que 93,3\% dos agricultores armazenam os agrotóxicos distante de alimentos, 90,0\% longe de fontes de água e 76,7\% em local fechado (BOHNER et al., 2013). No estudo de Castro et al. (2011) foi analisado o uso de agrotóxicos em dois assentamentos de reforma agrária em Russas (CE), e os pesquisadores verificaram que grande parte dos entrevistados armazenava os agrotóxicos em suas casas, ou o depositava fora, junto a outros materiais, sem estabelecer uma distância mínima de segurança, situação diferente do que afirmam os agricultores de Imigrante.

Quando questionados sobre a disposição dos restos do agrotóxico preparado, 96 agricultores $(73,8 \%)$ afirmam não haver sobra de produtos, sendo comum a prática de percorrer novamente a plantação e refazer a aplicação até que não sobre mais nada no pulverizador. Atitude esta que demonstra que os agricultores não utilizam a quantidade prescrita para a área e, na ilusão de não perder o produto e, consequentemente, o valor investido no mesmo, aplicam quantidades superiores às necessárias. Outros 31 participantes $(23,8 \%)$ relataram utilizar as sobras em outra aplicação e outros três agricultores $(2,4 \%)$ disseram jogar as sobras no solo. Situação semelhante foi encontrada nos estudos de Preza e Augusto (2012), em que 55,2\% relatam não haver sobra de produto, $41,3 \%$ as utilizam em outra aplicação e 3,5\% mencionam jogá-las no solo.

O relato da ausência de sobras após a aplicação muitas vezes ocorre não pelo cálculo correto da quantidade a ser empregada, mas pela reaplicação, o que pode acarretar em uma aplicação com quantidades superiores às realmente necessárias para os cultivos (PREZA \& AUGUSTO, 2012). No que diz respeito à reutilização das sobras do produto, sabe-se que estes não devem ser armazenados após preparo, pois se desconhece os efeitos à saúde das interações químicas e dos subprodutos gerados nessas misturas ( PREZA \& AUGUSTO, 2012).

A prática de lavar as embalagens vazias está relacionada com a diminuição dos riscos de contaminação do meio ambiente e também sua proteção. Ainda permite o aproveitamento integral do produto (QUINTELA, 2004). Conforme o $\S 5^{\circ}$ do art. 53 do Decreto Federal $n^{\circ}$ 4.074/2002 (BRASIL, 2002), as embalagens rígidas, que contiverem formulações miscíveis ou dispersíveis em água, deverão ser submetidas pelo usuário à operação de tríplice lavagem, ou tecnologia equivalente, conforme orientação constante de seus rótulos, bulas ou folheto complementar. No presente estudo, 98 agricultores $(75,4 \%)$ relataram realizar a tríplice lavagem das embalagens. Em outro estudo, foi encontrado um índice mais alto, em que 93,3\% dos entrevistados disseram realizá-la (BOHNER et al., 2013). Essa prática, apesar de ser difundida e prescrita, ainda não foi incorporada por muitos produtores, que não veem nela uma forma de diminuição dos danos causados ao meio ambiente. Em estudo de Carneiro et al. (2004), na cidade de Guaíra (SP), técnicos do Centro de Vigilância Sanitária relataram frequentemente recoIher nas matas e nos acostamento de rodovias regionais embalagens descartadas de agrotóxicos, sem qualquer norma de segurança.

Sobre a devolução das embalagens de agrotóxico, 67 agricultores $(51,5 \%)$ relatam devolvê-las em coleta realizada pelo município, outros três agricultores $(2,3 \%)$ devolvem as embalagens na loja de insumos agrícolas, um agricultor $(0,8 \%)$ devolve as embalagens 
na cooperativa e 59 agricultores $(45,4 \%)$ dizem dar outro destino às embalagens. Dentre estes últimos a maioria $(81,4 \%)$ armazena-as em algum lugar da propriedade, $13,6 \%$ afirmam queimar as embalagens, $3,4 \%$ enterram em algum lugar da propriedade e 1,7\% as destinam para o lixo comum.

Preza e Augusto (2012) encontraram percentuais semeIhantes em estudo realizado no município de Conceição do Jacuípe (BA), onde $62 \%$ dos entrevistados relatam devolver as embalagens vazias nas lojas de insumos agrícolas e $31 \%$ as descartam inadequadamente no campo.

Delgado e Paumgartten (2004), em estudo realizado em Paty do Alferes (RJ), em 1997, verificaram que não existia um padrão quanto à prática de descarte das embalagens de agrotóxicos, que muitas vezes eram inutilizadas de maneira incorreta (enterradas, deixadas na própria lavoura, jogadas na mata), contribuindo para contaminação ambiental.

No Brasil, para a correta destinação das embalagens vazias de agrotóxicos foi criado o Instituto Nacional de Processamento de Embalagens Vazias (INPEV), visando o atendimento às exigências da Lei Federal $\mathrm{n}^{0}$ 9.974/2000 (BRASIL, 2000), regulamentada dois anos depois pelo Decreto Federal $n^{\circ} 4.074$ (BRASIL, 2002), que passou a distribuir responsabilidades dentro da cadeia produtiva agrícola, ou seja, entre agricultor, fabricante e sistema de comercialização. Observa-se, no município de Imigrante, que muitos agricultores ainda não cumprem essa lei, pois quase metade deles $(45,4 \%)$ não destina corretamente as embalagens de agrotóxicos.

Alguns estudos estabelecem relações entre a exposição aos agrotóxicos e prejuízos à saúde humana. No estudo realizado em Minas Gerais, constatou-se, mediante análise sanguínea, que $50 \%$ dos trabalhadores entrevistados estavam intoxicados (SOARES et al., 2003). Os dados referentes aos agricultores de Imigrante permitiram a realização de uma relação entre os sintomas relatados por eles nos últimos seis meses e a relação destes com o uso de agrotóxicos. Entre os entrevistados, $73,3 \%$ relatam ter sentido ao menos um dos sintomas, sendo que o mais citado foi dor de cabeça $(70,2 \%)$, seguido por cansaço $(52,1 \%)$, conforme apresentado no gráfico a seguir (Figura 2).

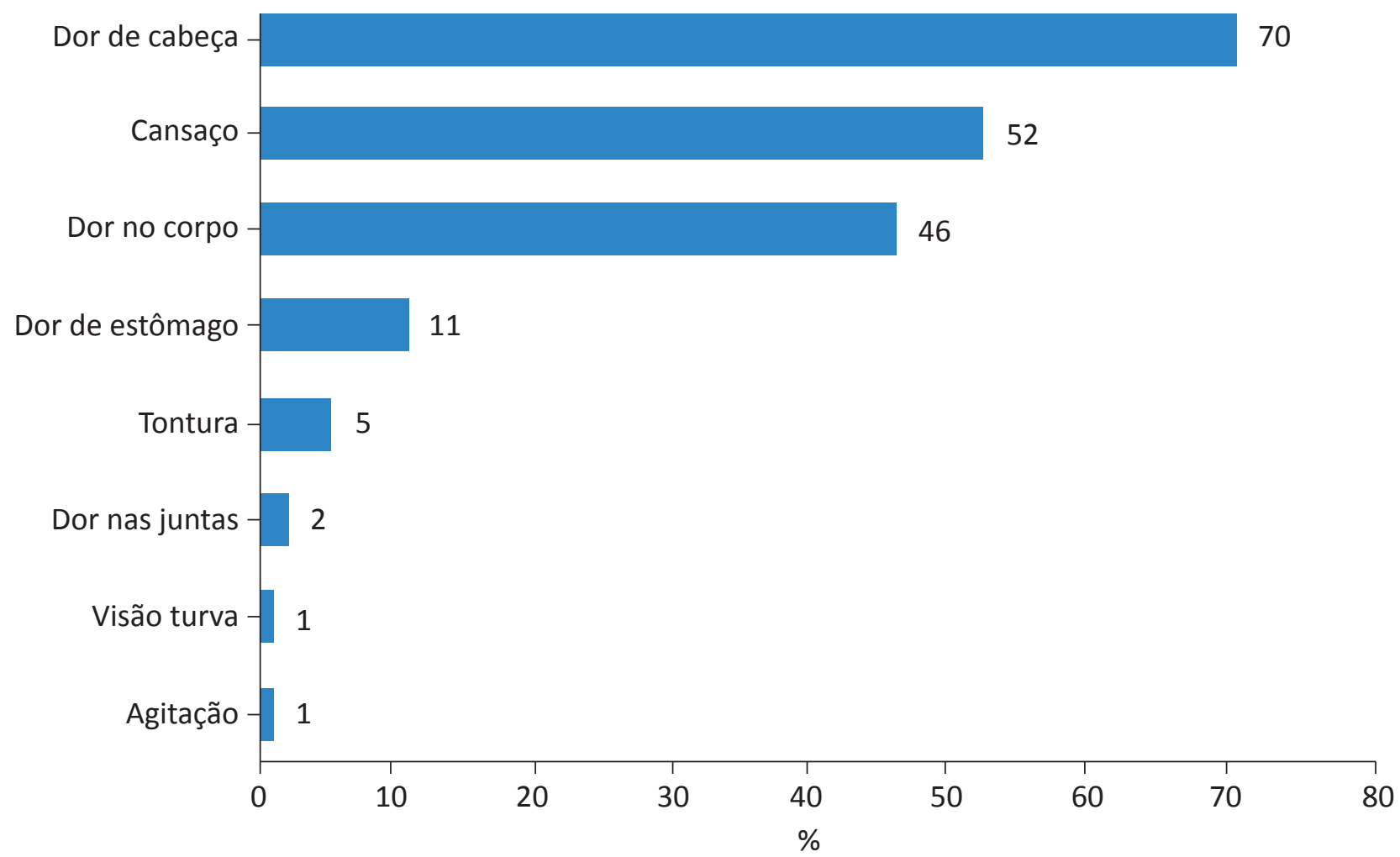

Figura 2 - Sintomas sentidos pelos agricultores do município de Imigrante (RS) nos últimos 6 meses. 
Dos $73,3 \%$ que mencionaram ter sentido ao menos um dos sintomas 17 agricultores $(18,1 \%)$ acreditam que estes podem ter alguma relação com o uso de agrotóxicos.

Quando questionados se ao longo da vida já haviam sentido algum mal-estar por ter usado agrotóxicos, 54 agricultores $(41,5 \%)$ responderam que sim, sendo que dor de cabeça foi novamente o sintoma de intoxicação mais citado $(55,6 \%)$, seguido por enjoo $(48,1 \%)$ e fraqueza $(11,1 \%)$ conforme apresentado no gráfico da Figura 3.

Em estudo realizado em uma comunidade agrícola de Nova Friburgo (RJ) por Peres et al. (2004) coloca-se que, segundo os entrevistados, os principais sintomas de intoxicação são dor de cabeça, dor de barriga e tontura, corroborando com os sintomas descritos pelos agricultores de Imigrante. Preza e Augusto (2012) mencionam que $44,8 \%$ dos entrevistados referiram alguma queixa de saúde durante a aplicação de agrotóxicos e dor de cabeça também foi o sintoma mais citado.

Outros estudos identificaram como fatores de risco para intoxicação por agrotóxicos o não uso de equipamentos de proteção individual (EPIs) e o curto intervalo de tem- po entre as recorrentes manipulações dos agrotóxicos (BEDOR et al., 2009; RECENA \& CALDAS, 2008; SOARES et al., 2003). A legislação brasileira sobre EPI é a Norma Regulamentadora $n^{0} 6$ (NR-6). A NR- 6 considera EPI todo dispositivo ou produto de uso individual utilizado pelo trabalhador, destinado à proteção de riscos suscetíveis de ameaçar a segurança e a saúde no trabalho.

Dentre todos os agricultores participantes da pesquisa em Imigrante, 118 (90,8\%) utilizam algum tipo de equipamento de proteção individual (EPI), enquanto 12 $(9,2 \%)$ não utilizam nenhum tipo de EPI. Destes que utilizam EPIs, 95,0\% usam botas; 93,3\% usam roupa longa (calça e camisa de manga longa) e apenas 1,7\% utilizam viseira, como pode ser visto na Figura 4. Bohner et al. (2013) encontraram resultados semelhantes, ou seja, $83,7 \%$ dos entrevistados usam algum tipo de EPI e 16,3\% não utilizam nenhum tipo de EPI; a bota também foi o EPI mais citado, que 99,0\% afirmam usar.

No estudo de Preza e Augusto (2012), 72,4\% dos agricultores afirmam usar algum EPI, enquanto $27,6 \%$ não utilizam nenhum tipo de EPI. Já Gregolis et al. (2012) relatam que, em seu estudo com agricultores do Acre,

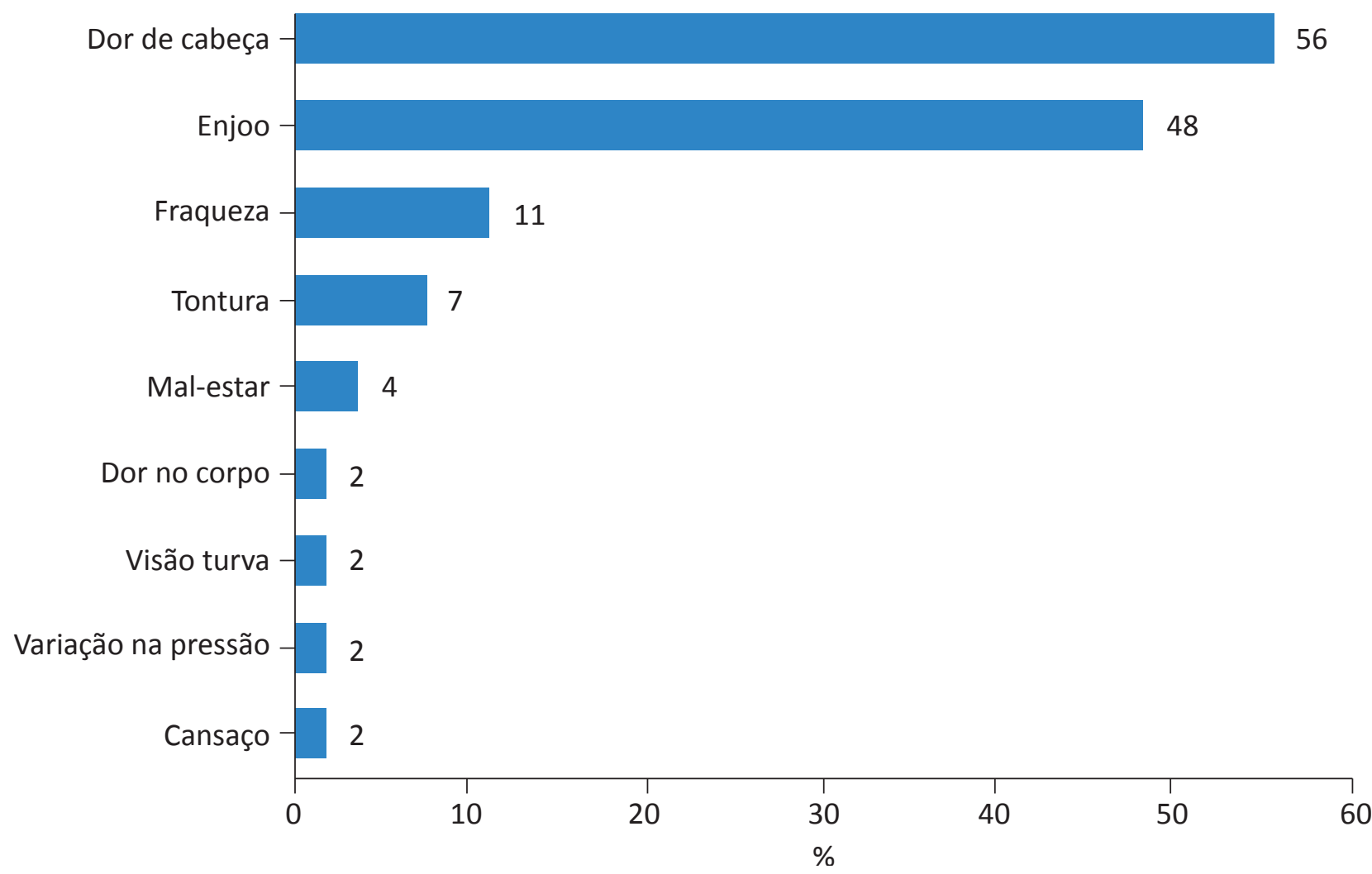

Figura 3 - Sintomas de intoxicação sentidos pelos agricultores do município de Imigrante (RS), atribuídos à utilização de agrotóxicos. 
a maioria dos indivíduos pesquisados afirma usar EPI somente "às vezes" na pulverização de agrotóxicos, apresentando como razões para não utilizá-lo com frequência o fato de:

- não precisarem (13 indivíduos);

- não possuírem os equipamentos de proteção indicados (8);

- não se preocuparem (4);

- atrapalha (2); e

- falta de orientação (2).

Estudos relatam que os agricultores consideram o uso do EPI uma prática importante, mas grande parte ainda não faz uso, ou utiliza apenas alguns dos EPIs necessários (RECENA \& CALDAS, 2008; BEDOR et al., 2009). Agricultores entrevistados por Soares et al. (2003) conferem essa deficiência à dificuldade de locomoção, desconforto e calor excessivo. Fonseca et al. (2007) apontaram como principal motivo para a não adoção de EPI o relato dos agricultores de que a pulverização é uma tarefa rápida e que, por isso, não havia a necessi- dade do uso de equipamento de proteção, mesmo que fosse repetida semanalmente, ao longo de toda uma vida de trabalho.

Em relação à leitura e compreensão do rótulo e da bula dos agrotóxicos, apenas 43 agricultores $(33,1 \%)$ relatam ler e compreendê-los, enquanto 87 (66,9\%) não leem ou não compreendem. Resultado semelhante é relatado por Bohner et al. (2013), que afirmam que $70 \%$ dos entrevistados não compreendem todas as informações contidas na bula, e por Oliveira-Silva et al. (2001), que constataram, em sua pesquisa, que $64,0 \%$ dos agricultores entrevistados no município de Magé (RJ) não realizavam a leitura dos rótulos dos produtos. Em estudo realizado por Santos et al. (2012) com agricultores familiares do assentamento Aroeira de Santa Terezinha (PB), apenas 13,64\% dos entrevistados afirmam ler o rótulo, mas não seguem as instruções por não compreenderem o que está escrito.

Uma das causas responsáveis pelo uso inadequado de agrotóxicos é a não observação das instruções e orientações contidas no rótulo e bula dos produtos (GARCIA \& ALVES FILHO, 2005). Oliveira-Silva et al. (2001) apontam que os níveis de escolaridade aliados à linguagem técnica das informações contidas no rótulo e bula jus-

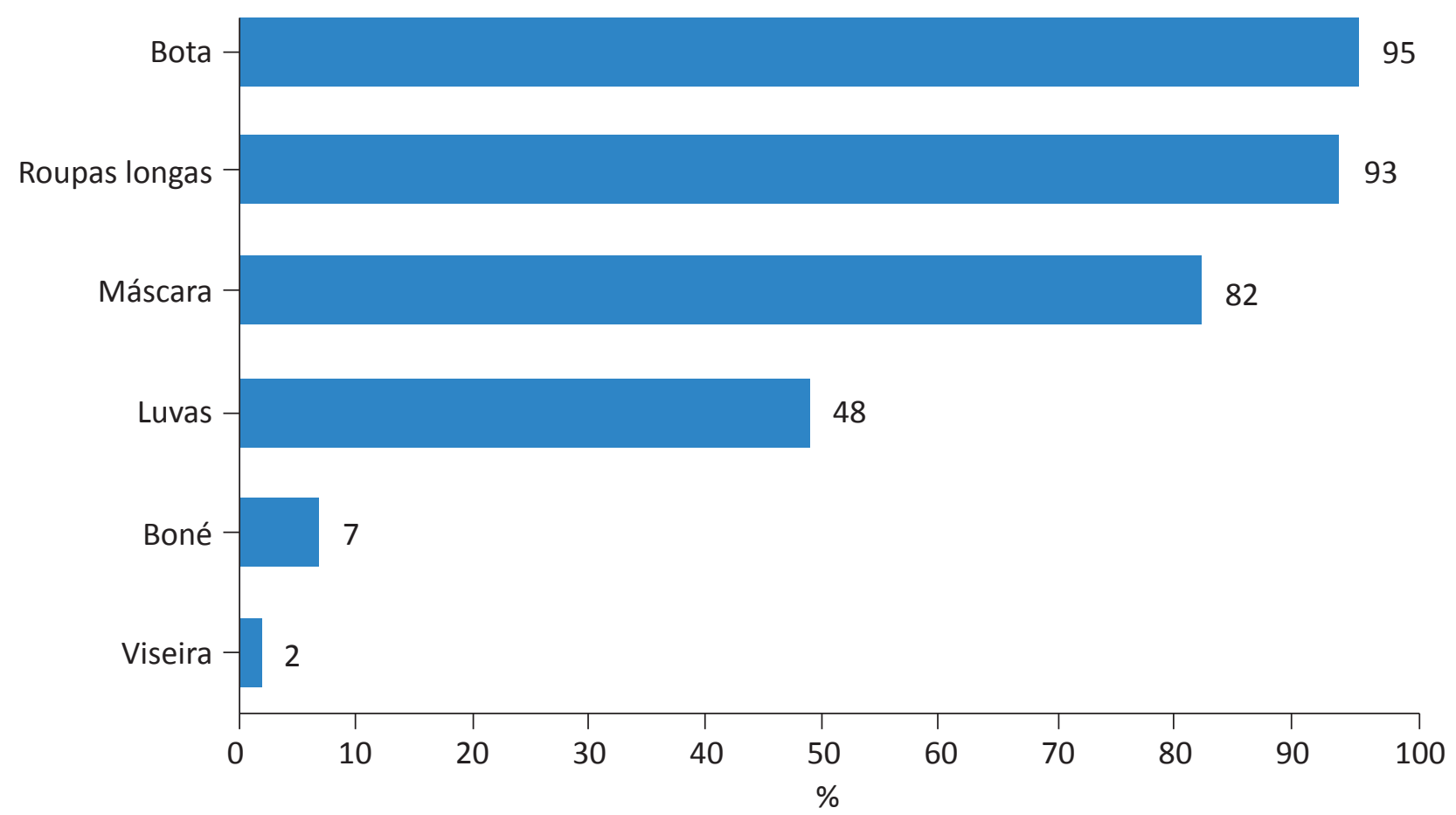

Figura 4 - EPIs utilizados pelos agricultores do município de Imigrante (RS). 
tificam a deficiência na compreensão das informações pelos agricultores. No município de Imigrante, nenhum dos agricultores se declarou analfabeto, mas a maioria $(83,1 \%)$ possui apenas o Ensino Fundamental incompleto, o que pode contribuir para o fato de menos da metade dos agricultores $(33,1 \%)$ ler ou compreender o rótulo e a bula dos agrotóxicos.

No estudo de Waichman et al. (2007) sobre a associação entre o nível educacional e a leitura voluntária do rótulo do produto, concluiu-se que os mesmos não estão relacionados, uma vez que até os agricultores com mais anos de estudo não têm esse hábito. No mesmo estudo, os agricultores descreveram como principais limitantes quanto à leitura dos rótulos, sendo o uso de termos técnicos, a falta de clareza nas informações e a utilização de letras "miúdas", que dificultam a leitura (WAICHMAN et al., 2007).
Quando questionados sobre os procedimentos de higiene pessoal após contato com os agrotóxicos, 115 agricultores $(88,5 \%)$ relatam tomar banho logo depois da aplicação do produto. Dos que utilizam algum EPI, 118 (90,8\%) relatam lavá-lo separadamente das roupas comuns. Resultados diferentes foram encontrados em estudo realizado por Santos et al. (2012) em que apenas pouco mais da metade $(59,09 \%)$ dos entrevistados relatam tomar banho após a aplicação do agrotóxico. A Cartilha sobre Agrotóxicos, distribuída pela Anvisa (2011), explica que é necessário tomar banho com sabão e bastante água corrente em caso de mal-estar após manuseio ou aplicação do agrotóxico, bem como indica a procura por ajuda médica. Além desses cuidados, essa cartilha também orienta aos agricultores que lavem as mãos sempre que puderem e bebam bastante água antes de trabalhar com os agrotóxicos e depois de se lavar.

\section{CONSIDERAÇÕES FINAIS}

De maneira geral, os resultados obtidos revelam que existe um quadro de exposição humana e ambiental aos agrotóxicos. Grande parte dos agricultores afirma conhecer os riscos que essa exposição pode ocasionar, porém, é notável o uso parcial dos EPIs, bem como a não leitura e compreensão do rótulo e da bula dos agrotóxicos pela maioria dos agricultores, e, aliado a isso, observa-se que quase metade dos entrevistados já sentiu algum sintoma de intoxicação.

O descarte inadequado das embalagens também é uma preocupação constante em relação à atividade agrícola, pois contribui para a contaminação das águas superficiais e subterrâneas, podendo expor parte da população aos efeitos desses compostos.
Os dados obtidos neste trabalho mostram que os estudos de percepção de riscos são importantes instrumentos para a gestão ambiental e controle dos riscos associados ao uso de agrotóxicos no trabalho rural. O resultado alcançado aponta para a importância de implementação de políticas públicas que incentivem a prática agrícola mais sustentável e que reduza a vulnerabilidade a que os agricultores e o meio ambiente estão expostos.

É necessário, ainda, que se desfaça a visão de que o uso de agrotóxicos é inevitável, incentivando o enfoque agroecológico e o desenvolvimento de práticas agrícolas sustentáveis, assim contribuindo para a manutenção da capacidade produtiva e diminuindo os efeitos negativos que os agrotóxicos causam à saúde humana e ao meio ambiente.

\section{REFERÊNCIAS}

AGÊNCIA NACIONAL DE VIGILÂNCIA SANITÁRIA - ANVISA. A Anvisa na redução à exposição involuntária à fumaça do tabaco. Brasília: Anvisa, 2009.

. Cartilha sobre agrotóxicos. Brasília: Anvisa, 2011. (Série Trilhas do Campo).

ALVES, J. D. N.; OlIVEIRA, S. S.; MOTA, A. M.; ALMEIDA, R. H. C.; OKUMURA, R. S. Percepção de riscos do uso de agrotóxicos na cultura da laranja pela comunidade do Cubiteua, município de Capitão Poço - PA. Enciclopédia Biosfera, Goiânia, v. 9, n. 17, p. 3594-3602, 2013. 
ANDRADE, S. R. Gestão das práticas de saúde na perspectiva do cuidado complexo. Texto \& Contexto Enfermagem, Florianópolis, v. 15, n. 3, p. 483-491, 2006.

BEDOR, C. N. G.; RAMOS, L. O.; PEREIRA, P. J.; RÊGO, M. A. V.; PAVÃO, A. C.; AUGUSTO, L. G. S. Vulnerabilidades e situações de riscos relacionados ao uso de agrotóxicos na fruticultura irrigada. Revista Brasileira de Epidemiologia, São Paulo, v. 12, n. 1, p. 39-49, 2009.

BOHNER, T. O. L.; ARAÚJO, L. E. B.; NISHIJIMA, T. O impacto ambiental do uso de agrotóxicos no meio ambiente e na saúde dos trabalhadores rurais. Revista Eletrônica do Curso de Direito, Santa Maria, v. 8, n. especial, p. 329-341, 2013. Disponível em: <http://cascavel.ufsm.br/revistas/ojs-2.2.2/index.php/revistadireito/article/view/8383/5075\#.VikkwDnc>. Acesso em: 23 ago. 2015.

BRASIL. Decreto Federal $n^{\circ}$ 4.074, de 4 de janeiro de 2002. Disponível em: <http://www.planalto.gov.br/ccivil_03/ decreto/2002/d4074.htm>. Acesso em: 16 maio 2017.

. Lei Federal no 7.802, de 11 de julho de 1989. Disponível em: <http://www.planalto.gov.br/ccivil_03/LEIS/ L7802.htm>. Acesso em: 16 maio 2017.

. Lei Federal n 9.974, de 6 de junho de 2000. Disponível em: <http://www.planalto.gov.br/ccivil_03/LEIS/L9974. htm>. Acesso em: 16 maio 2017.

CARNEIRO, R. M. A.; TAKAYANAGUI, A. M. M.; NERY, A. A.; BARBOSA, A. L. M. Experiências municipais sobre resíduos perigosos: avaliação, percepção e comunicação de riscos. Revista Brasileira de Ciências Ambientais, São Paulo, n. 2, p. 5-13, 2004.

CASTRO, M. G. G.; FERREIRA, A. P.; MATTOS, I. E. Uso de agrotóxicos em assentamentos de reforma agrária no município de Russas (Ceará, Brasil): um estudo de caso. Epidemiologia e Serviços de Saúde, Brasília, v. 20, n. 2, p. 245-254, 2011.

DELGADO, I. F.; PAUMGARTTEN, F. J. R. Intoxicações e uso de pesticidas por agricultores do Município de Paty do Alferes, Rio de Janeiro, Brasil. Cadernos de Saúde Pública, Rio de Janeiro, v. 20, n. 1, p. 180-186, 2004.

FONSECA, M. G. U.; PERES, F.; FIRMO, J. O. A.; UCHÔA, E. Percepção de risco: maneiras de pensar e agir no manejo de agrotóxicos. Ciência \& Saúde Coletiva, Rio de Janeiro, v. 12, n. 1, p. 39-50, 2007.

GARCIA, E. G.; ALVES FILHO, J. P. Aspectos de prevenção e controle de acidentes no trabalho com agrotóxicos. São Paulo: Fundacentro, 2005.

GREGOLIS, T. B. L.; PINTO, W. K.; PERES, F. Percepção de riscos do uso de agrotóxicos por trabalhadores da agricultura familiar do município de Rio Branco, AC. Revista Brasileira de Saúde Ocupacional, São Paulo, v. 37, n. 125, p. 99-113, 2012.

INSTITUTO BRASILEIRO DE GEOGRAFIA E ESTATÍSTICA - IBGE. Cidades. Disponível em: <http://cidades.ibge.gov.br/ xtras/perfil.php?lang=\&codmun=431036\&search=rio-grande-do-sul |imigrante>. Acesso em: 11 set. 2015.

LEITE, M. F.; SERRA, J. C. V. Avaliação dos impactos ambientais na aplicação dos agrotóxicos. Ambiência, Guarapuava, v. 9, n. 3, p. 675-682, 2013.

LYZNICKI, M. S. Educational and information strategies to reduce pesticide risks. Preventive Medicine, Montreal, v. 26, p. 191-200, 1997.

MENICUCCI, T. M. G. O Sistema Único de Saúde - 20 anos: balanço e perspectivas. Cadernos de Saúde Pública, Rio de Janeiro, v. 25, n. 7, p. 1620-1625, 2009. 
MOREIRA, J. C.; JACOB, S. C.; PERES, F.; LIMA, J. S.; MEYER, A.; OLIVEIRA-SILVA, J. J. Avaliação integrada do impacto do uso de agrotóxicos sobre a saúde humana em uma comunidade agrícola de Nova Friburgo, RJ. Ciência \& Saúde Coletiva, Rio de Janeiro, v. 7, n. 2, p. 299-311, 2002.

OLIVEIRA-SILVA, J. J.; ALVES, S. R.; MEYER, A.; PEREZ, F.; SARCINELLI, P. N.; MATTOS, R. C. O C.; MOREIRA, J. C. Influência de fatores socioeconômicos na contaminação por agrotóxicos, Brasil. Revista de Saúde Pública, São Paulo, v. 35, n. 2, p. 130-135, abr. 2001. Disponível em: <http://www.scielo.br/scielo.php?script=sci_arttext\&pid=S0034$89102001000200005 \&$ Ing=en\&nrm=iso >. Acesso em: 19 jan. 2016.

ORGANIZAÇÃO MUNDIAL DE SAÚDE - OMS. Carta da Organização Mundial de Saúde. OMS, 1946. Disponível em: <http://www.direitoshumanos.usp.br/index.php/OMS-Organiza\%C3\%A7\%C3\%A3o-Mundial-da-Sa\%C3\%BAde/ constituicao-da-organizacao-mundial-da-saude-omswho.html/>. Acesso em: 16 dez. 2013.

PACHECO, P. Brasil lidera uso mundial de agrotóxicos. Estado de S. Paulo, São Paulo, 7 ago. 2009. Disponível em: <http:// economia.estadao.com.br/noticias/geral,brasil-lidera-uso-mundial-de-agrotoxicos,414820>. Acesso em: 12 ago. 2015.

PERES, F.; LUCCA, S. R.; PONTE, L. M. D.; RODRIGUES, K. M.; ROZEMBERG, B. Percepção das condições de trabalho em uma tradicional comunidade agrícola em Boa Esperança, Nova Friburgo, Rio de Janeiro, Brasil. Cadernos de Saúde Pública, Rio de Janeiro, v. 20, n. 4, p. 1059-1068, 2004.

PERES, F.; MOREIRA, J. C. (Orgs.). É veneno ou é remédio? Agrotóxicos, saúde e ambiente. Rio de Janeiro: Fiocruz, 2003. 384 p. Disponível em: <http://books.scielo.org/id/sg3mt>. Acesso em: 23 set. 2015.

PREZA, D. L. C.; AUGUSTO, L. G. S. Vulnerabilidades de trabalhadores rurais frente ao uso de agrotóxicos na produção de hortaliças em região do Nordeste do Brasil. Revista Brasileira de Saúde Ocupacional, São Paulo, v. 37, n. 125, p. 89-98, jun. 2012. Disponível em: <http://www.scielo.br/scielo.php?script=sci_arttext\&pid=S0303-76572012000100012\&lng= en\&nrm=iso>. Acesso em: 19 jan. 2016.

QUINTELA, E. D. Manejo integrado dos insetos e outros invertebrados: pragas do feijoeiro. Informe Agropecuário, Belo Horizonte, v. 25, n. 223, p. 113-136, 2004.

RANGEL, C. F.; ROSA, A. C. S.; SARCINELLI, P. N. Uso de agrotóxicos e suas implicações na exposição ocupacional e contaminação ambiental. Cadernos de Saúde Coletiva, Rio de Janeiro, v. 19, n. 4, p. 435-442, 2011.

RECENA, M. C. P.; CALDAS, E. D. Percepção de risco, atitudes e práticas no uso de agrotóxicos entre agricultores de Culturama, MS. Revista de Saúde Pública, São Paulo, v. 42, n. 2, p. 294-301, 2008.

SANTOS, M. E. O.;SANTOS, H. C.; DANTAS, H. J. O uso indiscriminado de agrotóxico na agricultura familiar no assentamento Aroeira no município de Santa Terezinha-PB. In: CONGRESSO NORTE NORDESTE DE PESQUISA E INOVAÇÃO, 7, 2012, Palmas. Anais... Palmas: Instituto Federal de Educação, Ciência e Tecnologia, 2012. Disponível em: <http://propi.ifto. edu.br/ocs/index.php/connepi/vii/paper/view/4672/3051>. Acesso em: 12 set. 2015.

SEGRE, M.; FERRAZ, F. C. O conceito de saúde. Revista de Saúde Pública, São Paulo, v. 31, n. 5, p. 538-542, 1997.

SILVA, J. M.; NOVATO-SILVA, E.; FARIA, H. P.; PINHEIRO, T. M. M. Agrotóxico e trabalho: uma combinação perigosa para a saúde do trabalhador rural. Ciência \& Saúde Coletiva, Rio de Janeiro, v. 10, n. 4, p. 891-903, 2005.

SIQUEIRA, S. L.; KRUSE M. H. L. Agrotóxicos e saúde humana: contribuição dos profissionais do campo da saúde. Revista da Escola de Enfermagem da USP, São Paulo, v. 42, n. 3, p. 584-590, 2008.

SOARES, W.; ALMEIDA, R. M. V. R.; MORO, S. Trabalho rural e fatores de risco associados ao regime de uso de agrotóxicos em Minas Gerais, Brasil. Cadernos de Saúde Coletiva, Rio de Janeiro, v. 19, n. 4, p. 1117-1127, 2003. 
SOARES, W. L.; FREITAS, E. A. V.; COUTINHO, J. A. G. Trabalho rural e saúde: intoxicações por agrotóxicos no município de Teresópolis - RJ. Revista de Economia e Sociologia Rural, Brasília, v. 43, n. 4, p. 685-701, 2005.

SOUZA, A.; MEDEIROS, A. R.; SOUZA, A. C.; WINK, M.; SIQUEIRA, I. R.; FERREIRA, M. B. C.; FERNANDES, L.; LOAYZA HIDALGO, M. P.; TORRES, I. L. S. Avaliação do impacto da exposição a agrotóxicos sobre a saúde de população rural: Vale do Taquari (RS, Brasil). Ciência e Saúde Coletiva, Rio de Janeiro, v. 16, n. 8, p. 3519-3528, ago. 2011. Disponível em: $<$ http://www.scielo.br/scielo.php?script=sci_arttext\&pid=S1413-81232011000900020\&lng=en\&nrm=iso>. Acesso em: 19 jan. 2016.

STOPPELLI, I. M. B. S.; MAGALHÃES, C. P. Saúde e segurança alimentar: a questão dos agrotóxicos. Ciência e Saúde Coletiva, Rio de Janeiro, v. 10, p. 91-100, 2005.

TROIAN, A.; OLIVEIRA, S. V.; DALCIN, D.; EICHLER, M. L. O uso de agrotóxicos na produção de fumo: algumas percepções de agricultores da comunidade de Cândido Brum, no município de Arvorezinha (RS). In: CONGRESSO DA SOCIEDADE BRASILEIRA DE ECONOMIA, ADMINISTRAÇÃO E SOCIOLOGIA RURAL, 47, 2009, Porto Alegre. Anais... Porto Alegre: Sociedade Brasileira de Economia, Administração e Sociologia Rural, 2009. Disponível em: <http://www.sober.org.br/ palestra/13/844.pdf>. Acesso em: 24 ago. 2015.

VEIGA, M. M. Agrotóxicos: eficiência econômica e injustiça socioambiental. Ciência e Saúde Coletiva, Rio de Janeiro, v. 12, n. 1, p. 145-152, 2007.

WAICHMAN, A. V.; EVE, E.; SILVA, N.; NAILSON, C. Do farmers understand the information displayed on pesticide product labels? A key question to reduce pesticides exposure and risk of poisoning in the Brazilian Amazon. Crop Protection, Tehran, v. 26, n. 4, p. 576-583, 2007.

ZERWES, C. M.; SECCHI, M. I.; CALDERAN, T. B.; BORTOLI, J.; TONETTO, J. F.; TOLDI, M.; OLLIVEIRA, E. C.; SANTANA, E. R. R. Análise da qualidade da água de poços artesianos do município de Imigrante, Vale do Taquari/RS. Ciência e Natura, Santa Maria, v. 37, n. 4, p. 651-663, 2015. 